believing that the West is out to harm and destroy them. It is possible, however, to help. Since the 1975 Helsinki Accord, human rights in the USSR have become a legitimate concern of the West. The Soviet authorities wish to have a good public relations image, and respond to pressures for the release of individuals. Dissenters crave support from people in the West, and any doctor who has the opportunity of visiting Russia should always ensure that they see people who have suffered. The Soviets desire recognition by the international community of their scientific efforts. Contact should be made with those attending international scientific conferences from the USSR. It should be remembered however that they will be regarded as particularly trustworthy, or they would not have been granted permission to leave the country. The organisers of scientific meetings should not allow a paper to be read by a "spokesman", on the pretext that the original author was "unfortunately unwell" and therefore unable to attend. This nearly always means the original invitee is viewed with some suspicion and has been refused permission to travel.

The ensuing discussion was led by Professor Rawnsley. He gave his own initial reaction to allegations of Soviet psychiatric abuse as being the result of Western disinformation. He now realises however, that there is no doubt as to their validity. In the early 1980 s, when the Soviet authorities were under pressure from the WPA, there had been an improvement in the situation. Since the resignation of the Soviet psychiatric society from that body, he had hoped that a period out of the limelight would allow them to make further progress. The situation had worsened again, and it was as a result of this that he thought more publicity among British doctors should be achieved, so that pressure could be applied by them to end this abuse of psychiatry and indeed the whole of medicine.
Delegates to the conference expressed their thanks to the College for giving them the opportunity to learn more about the Russian situation. Some said they had not realised the extent of the problem. The degree of nonpsychiatric medical abuse was questioned. It was pointed out that although this is a reality, most often it is malpractice rather than abuse.

Personal contact was stressed as a valuable means of communication. Everyone should beware, however, that those allowed to travel are the ones with the regime's confidence. The role of the Government, in particular the Foreign Office was praised, but they needed reminding of the need for continued pressure. An interview with the new Soviet Ambassador was suggested and thought useful.

The possibility of international pressure was raised. The USSR has powerful friends and although the World Health Organisation had interested themselves in South Africa, they would probably not wish to be drawn into confrontation with the USSR.

The conference received a gratifying amount of publicity in the medical press. Hospital Doctor had an editorial, The Lancet had an informative paragraph, and the British Medical Journal a full page leading article.

In summing up the conference, Professor Rawnsley stated that he had taken heart from the evident interest of the medical profession, and their desire to change the situation in Russia, which is a disgrace to psychiatry and to medicine as a whole. He felt the time was right for continued pressure to achieve this change. This would come "trickle by trickle rather than as a sudden event".

* Dr Koryagin was released at the end of February 1987 and is now in his home town of Kharkov.

\title{
Incorporation of Private Hospitals in Public Funded Training Schemes
}

Following the report from the Collegiate Trainees' Committee on Manpower Control of Private Hospital Training Posts in England and Wales, Council have approved the Executive and Finance Committee's recommendation that, having accepted the need for manpower control, the College should not consider any new applications for private hospital training posts until such posts had received Regional Manpower Approval. This already occurs in new posts considered by JCHPT. The responsibility for applying for such approval would lie with the Private Hospitals.

\section{Differential in Registration Fees for Inceptors at Quarterly Meetings}

Council has approved the recommendation of the Programmes and Meetings Committee for a differential in registration fees for Inceptors at Quarterly Meetings, with a corresponding increase in fees for other Members of the College to cover the cost of this subsidy. 